BOSA, N.; CALVETE, E.O.; NIENOW, A.A.; SUZIN, M.; Enraizamento e aclimatização de plantas micropropagadas de gipsofila. Horticultura Brasileira, Brasília, v. 21, n. 2, p.207-210, abril-junho 2003.

\title{
Enraizamento e aclimatização de plantas micropropagadas de gipsofila ${ }^{1}$
}

Nair Bosa ${ }^{2}$; Eunice O. Calvete ${ }^{3}$; Alexandre Augusto Nienow ${ }^{3}$; Marilei Suzin $^{3}$

${ }^{2 / E A F S, ~ C . ~ P o s t a l ~ 21,99170-000, ~ S e r t a ̃ o-R S . ~}{ }^{3 / F A M V-U P F, ~ C . ~ P o s t a l ~ 611, ~ 99001-070 ~ P a s s o ~ F u n d o-R S ; ~ E-m a i l: ~ c a l v e t e u @ u p f . t c h e . b r ~}$

\section{RESUMO}

Na última década, o cultivo de flores de corte tem sido incrementado em função da facilidade em agregar valor ao produto final e, entre as ornamentais mais cultivadas, destaca-se a Gypsophila paniculata. A técnica da micropropagação vem sendo utilizada para a produção de mudas em escala comercial. O objetivo deste experimento foi reduzir ou eliminar a fase de enraizamento in vitro. Para tanto, foi avaliada a influência do regulador de crescimento Ácido Indolbutírico (AIB) durante a aclimatização ex vitro, em diferentes datas de enraizamento in vitro. Os tratamentos foram constituídos de um fatorial com 3 doses $\left(0 ; 500\right.$ e $1000 \mathrm{mg} . \mathrm{L}^{-1}$ de AIB) x 6 períodos $(5 ; 10 ; 15 ; 20 ; 25$ e 30 dias $)$ de enraizamento in vitro. Estes foram dispostos em um delineamento experimental de blocos ao acaso com quatro repetições e doze plântulas por parcela. As variáveis analisadas foram taxa de sobrevivência, volume de raízes, massa fresca e seca da parte aérea e da raiz. Os dados foram submetidos às análises de variância e de regressão. Os resultados indicaram que, para propagar Gypsophila paniculata, cultivar Bristol Fairy, há necessidade da fase de enraizamento in vitro, sendo que o período ideal situa-se entre 25-30 dias, para posterior transplantio. Por outro lado, nas doses estudadas, não houve efeito do regulador de crescimento (AIB).

Palavras-chave: Gypsophila paniculata, regulador de crescimento, ácido indolbutírico, plantas ornamentais.

\section{ABSTRACT \\ Rooting and aclimatization of micropropagated Gypsophila paniculata plants}

In the last decade, the cultivation of ornamental flowers for cutting increased as a result of the easiness of adding value to the final product. Among the most cultivated ornamental plant stands out the specie Gypsophila paniculata. The micropropagation technique has been used for young plant production on a commercial scale. The purpose of this experiment was to reduce or even eliminate the rooting phase in vitro. The influence of the indolbutyric acid (IBA), during six acclimatization periods, on rooting was evaluated. The treatments followed a factorial scheme with three dosis $(0 ; 500$ and $1000 \mathrm{mg} . \mathrm{L}^{-1}$ of IBA) x six periods $(5 ; 10 ; 15 ; 20 ; 25$ and 30 days) in vitro rooting. These factors were arranged in a randomized block design with four replicates and twelve shoots per plot. The survival, volume of roots, fresh and dry weight for aerial part and roots were evaluated. The data were submitted to analysis of variance and regression. To propagate Gypsophila paniculata, cv. Bristol Fairy, there is a need of in vitro rooting phase, and the ideal period is between 25-30 days for later transplantation. No effect of the growth regulator (IBA) was found.

Keywords: Gypsophila paniculata, growth regulator, indolbutyric acid, ornamental plants.

\section{(Recebido para publicação em 15 de maio de 2002 e aceito em 12 de fevereiro de 2003)}

$\mathrm{A}$ s ornamentais são, por excelência, grupo de plantas em que a aplicação da micropropagação teve uma expressão significativa no mundo científico, com repercussão direta na economia. O incentivo para esse crescimento, fundamenta-se no alto valor agregado ao produto final (Capellades-Queralt et al., 1993). Neste contexto, inclui-se a Gypsophila paniculata; uma flor de corte de grande importância na floricultura comercial, por ser um dos componentes principais na confecção de arranjos.

Dentre as técnicas de cultura de tecidos, a micropropagação é a que apresenta melhor alternativa para produção de mudas de alta qualidade, além de proporcionar grande número de plantas em espaço e tempo reduzidos e em qualquer época do ano.
A passagem das plantas desenvolvidas in vitro para o ambiente ex vitro é denominada de aclimatização. Esta etapa, entretanto, pode chegar a ser um fator limitante no processo da micropropagação (Grattapaglia \& Machado, 1998). Portanto, para uma melhor resposta na aclimatização, deve-se proporcionar alta umidade relativa do ar, baixa irradiação e temperatura amena (Debergh, 1991). Além disso, as raízes produzidas in vitro são fracas e pouco funcionais, razão pela qual devem ser substituídas o mais rapidamente possível, o que só ocorrerá mantendo a planta com baixa transpiração (Pierik, 1990). Por outro lado, George (1996) observou que raízes formadas in vitro não se desenvolvem adequadamente para muitas espécies micropropagadas.
A eliminação da etapa de enraizamento in vitro é desejável sob o aspecto econômico (Debergh \& Maene, 1981), pois o período em que a muda permanece na sala de cultura, a mão-deobra utilizada e os gastos com energia elevam o custo da muda micropropagada. Segundo Grattapaglia \& Machado (1998), a qualidade do sistema de raízes é beneficiada, visto que, na fase de aclimatização, este tende a ser mais desenvolvido e funcional. Uma análise comparativa do enraizamento in vitro e ex vitro de miniaturas de rosas foi realizada por Rogers \& Smith (1992), os quais observaram que raízes produzidas in vitro eram grossas, quebradiças, inflexíveis e levemente escuras, ao passo que as produzidas ex vitro eram finas, flexíveis, brancas e

1 Parte integrante da dissertação de mestrado do primeiro autor, realizada na FAMV/UPF. 
ramificadas. A análise histológica demonstrou a superioridade da área vascular no enraizamento ex vitro.

Segundo George (1996), a presença de auxina é necessária para a indução do enraizamento em segmentos caulinares. Plantas que respondem à ausência de auxina exógena possuem, presumivelmente, suficientes níveis endógenos. Assim, em algumas espécies pode ser dispensado o uso de auxinas no enraizamento, conforme Seganfredo et al. (1995); Rohr \& Hanus, citado por Assis \& Teixeira, (1998); Carvalho et al. (1999); Moreira et al. (2000). As auxinas são muito utilizadas na indução de raízes por promoverem o desenvolvimento das raízes adventícias, principalmente de espécies ornamentais, pois as características de interesse comercial são mantidas (Tagliacozzo, 1998). Diversas auxinas, isoladamente ou em combinação, podem ser utilizadas no enraizamento da maioria das espécies. As auxinas mais utilizadas são o ácido indolbutírico (AIB), o ácido naftalenoacético (ANA) e o ácido indol acético (AIA). Estimular a iniciação e formação do tecido meristemático e atuar na elongação dos tecidos que darão origem aos primórdios de raízes são funções das auxinas. Para determinar o melhor regulador e a concentração ideal, há necessidade de experimentos, visto que as espécies respondem de forma diferenciada (Hartmann \& Kester, 1990).

Constata-se na prática que há necessidade de otimizar o processo do cultivo in vitro de Gypsophila paniculata no que se refere à fase de enraizamento, pois observa-se que raízes que se desenvolvem in vitro são danificadas ao serem removidas dos frascos por ocasião da aclimatização.

Visando otimizar a produção de mudas de Gypsophila paniculata, objetivou-se reduzir ou eliminar a fase de enraizamento in vitro, avaliando a influência de doses do regulador de crescimento AIB durante o enraizamento ex vitro em diferentes períodos de permanência in vitro.

\section{MATERIAL E MÉTODOS}

O experimento foi desenvolvido no Laboratório de Biotecnologia Vegetal (fase de indução e/ou enraizamento in vitro) e em ambiente protegido com polietileno no Setor de Hortaliças (fase de aclimatização e enraizamento ex vitro) da Faculdade de Agronomia e Medicina Veterinária da Universidade de Passo Fundo.

Para a primeira fase, utilizou-se como explantes plantas micropropagadas de Gypsophila paniculata, cultivar Bristol Fairy, com aproximadamente $2 \mathrm{~cm}$ de altura. Posteriormente, as plântulas foram submetidas a três subcultivos sucessivos durante a fase de multiplicação. Foram a seguir transferidas para meio MS (Murashige \& Skoog, 1962) acrescido de $0,5 \mathrm{mg} \mathrm{L}^{-1}$ de AIB, $30 \mathrm{~g} \mathrm{~L}^{-1}$ de sacarose e $6,0 \mathrm{~g} \mathrm{~L}^{-1}$ de ágar, em seis diferentes períodos de enraizamento (5; $10 ; 15 ; 20 ; 25$ e 30 dias).

$\mathrm{Na}$ segunda fase, após serem retiradas dos frascos, a base das mudas foi mergulhada por cinco segundos em solução contendo água destilada (testemunha), 500 e 1000 mg.L L $^{-1}$ de AIB. Após, foram levadas para a estufa plástica e transplantadas para substrato contendo casca de arroz carbonizada, em bandejas de poliestireno expandido, com 72 células de $110 \mathrm{~cm}^{3}$. Após o transplante, as plantas foram mantidas em condições de aproximadamente $80 \%$ de umidade relativa do ar, temperatura média de $25^{\circ} \mathrm{C}$ sob sistema de nebulização intermitente, regulada por timer automático, com intervalos de 10 minutos a cada 10 segundos de nebulização. Duas aplicações de nutrientes foram realizadas durante a execução do experimento. A solução nutritiva foi à base dos componentes da solução estoque do meio MS citado por Caldas et al. (1998), nas quantidades de $1 \mathrm{ml} . \mathrm{L}^{-1}$ das soluções E, $\mathrm{F}$ e $\mathrm{G} ; 2$ ml.L $\mathrm{L}^{-1}$ das soluções D e H; 4 ml. $\mathrm{L}^{-1}$ da solução A e 5 ml. $\mathrm{L}^{-1}$ das soluções B e C. Antes da aplicação, a solução foi diluída em cinco litros de água.

Os tratamentos foram dispostos em fatorial com 6 períodos de enraizamento in vitro $(5 ; 10 ; 15 ; 20 ; 25$ e 30 dias $) \times 3$ doses $\left(0 ; 500\right.$ e 1000 mg. L $^{-1}$ de AIB) em um delineamento experimental de blocos ao acaso, com quatro repetições. Cada parcela constou de 12 plântulas, perfazendo um total de 864 . A avaliação foi realizada aos trinta dias após o transplante, por intermédio das variáveis: taxa de sobrevivência (\%), volume de raiz $\left(\mathrm{cm}^{3}\right)$, massa fresca e seca da parte aérea e das raízes (mg). A determinação do volume foi realizada colocando-se as raízes em proveta graduada, contendo um volume conhecido de água. Pela diferença, obteve-se a resposta direta do volume de raízes, pela equivalência de unidades $\left(1 \mathrm{ml}=1 \mathrm{~cm}^{3}\right)$, segundo metodologia descrita por Basso (1999).

Utilizando-se os dados da massa seca da parte aérea (MSA) e da raiz (MSR), determinou-se a taxa de crescimento (TC) em mg/5 dias, de acordo com Benincasa (1988), conforme a equação abaixo.

$$
T C=\frac{P_{2}-P_{1}}{T_{2}-T_{1}}
$$

Onde:

$P_{2}-P_{1}=$ pesos da matéria seca em duas avaliações sucessivas; $T_{2}-T_{1}=$ variação no tempo.

Os dados foram submetidos à análise de variância pelo teste $\mathrm{F}$ a $1 \%$ de significância e de regressão. $\mathrm{O}$ "ponto de máximo" das funções quadráticas foi encontrado através da equação: $-\mathrm{b} / 2 \mathrm{c}=1$

\section{RESULTADOS E DISCUSSÃO}

Não se observou efeito positivo, nas características avaliadas, das doses do regulador de crescimento AIB sobre as mudas de Gypsophila paniculata produzidas em diferentes períodos durante o enraizamento in vitro. Por outro lado, obteve-se resposta positiva para todas as variáveis estudadas na produção de mudas oriundas de diferentes datas de enraizamento in vitro durante a etapa de aclimatização.

A sobrevivência das plantas durante o período de aclimatização variou de $90 \%$ a $98 \%$ para plantas de 5 a 30 dias de enraizamento in vitro, respectivamente. A resposta foi linear crescente, mostrando, assim, a importância da permanência das plantas in vitro. Por outro lado, a maior taxa de sobrevivência encontrada no tratamento que permaneceu 30 dias no meio de enraizamento in vitro pode ter ocorrido pelo maior acúmulo de sólidos nos tecidos, conferindo maior resistência às folhas. 
O volume de raízes (Figura 1), apresentou um comportamento quadrático $\left(y=0,059+0,0155-0,0003 x^{2}\right)$. Notase, pela curva de regressão, uma tendência de maior volume de raízes para as mudas cujas plantas permaneceram entre 15 e 25 dias de enraizamento in vitro. $\mathrm{O}$ ponto de máximo na função quadrática indica que plantas com 25 dias de enraizamento in vitro atingem o volume máximo de enraizamento ex vitro, quando, então, tem início um decréscimo neste incremento. Esses resultados concordam com George (1996), o qual afirmou que algumas espécies, quando enraizadas in vitro, por ocasião da aclimatização, crescem melhor, apresentam maior taxa de sobrevivência e emitem novas raízes mais rapidamente.

Para massa fresca da parte aérea, houve um comportamento quadrático em relação aos dias de enraizamento in vitro durante a etapa de aclimatização, representada pela equação $\mathrm{y}=54,89+$ $29,05 \mathrm{x}-0,50 \mathrm{x}^{2}$ com $\mathrm{R}^{2}=0,93$ $(\mathrm{p}=0,055)$, evidenciando o maior acúmulo de massa fresca aos 28 dias (-b/2c), a partir dos quais começam reduzir a matéria e as reservas de energia.

Com relação à massa seca da parte aérea, os resultados expressaram resposta linear. Analisando a taxa de crescimento das mudas de Gypsophila paniculata, verifica-se que o maior acúmulo da massa seca das folhas foi observado nas mudas cujas plantas permaneceram entre 15 e 20 dias no meio de enraizamento in vitro, as quais apresentaram um incremento médio de 3,53 $\mathrm{mg} / 5$ dias. Nas plantas que ficaram entre 25 e 30 dias no meio de enraizamento in vitro, a taxa de crescimento foi de 1,48 $\mathrm{mg} / 5$ dias. Conforme Benincasa (1988), a taxa de crescimento pode indicar a velocidade média de crescimento ao longo do período observado. Carvalho et al. (1999) observaram, durante a aclimatização de plantas de cafeeiro enraizadas in vitro, que o cultivo nessa condição contribuiu para o desenvolvimento das raízes, porém não para o desenvolvimento da parte aérea.

Houve efeito dos diferentes dias em que as plantas foram mantidas em meio de enraizamento in vitro sobre a produção da massa fresca e seca da raiz ( $\mathrm{Fi}$ gura 2). O aumento da produção da

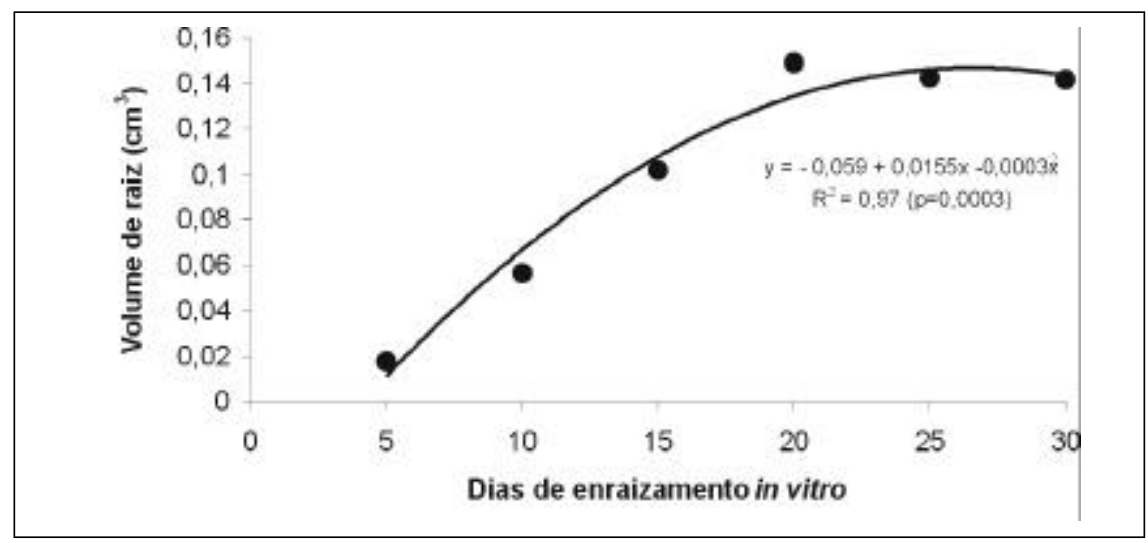

Figura 1. Volume de raiz de Gypsophila paniculata durante o período de 30 dias de aclimatização. Passo Fundo, UPF, 2001.

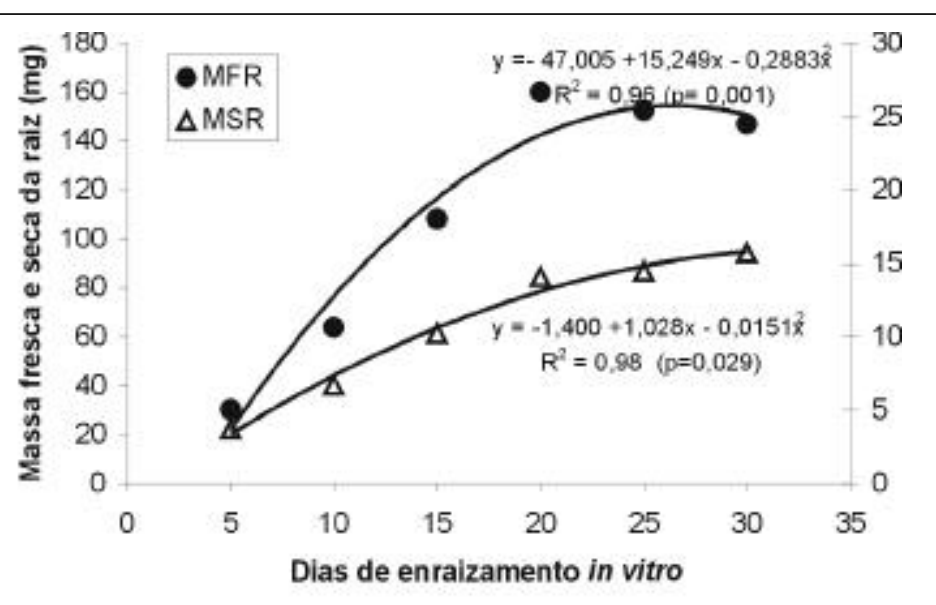

Figura 2. Massa fresca e seca de raiz de Gypsophila paniculata durante o período de 30 dias de aclimatização, Passo Fundo, UPF, 2001.

massa fresca da raiz foi crescente entre as datas utilizadas para enraizar até os 25 dias. Entretanto, aumentando para 30 dias, houve redução na massa fresca, conforme se observa pela análise de regressão $\left(\mathrm{R}^{2}=0,96\right)$. Calculando-se pela curva da equação quadrática, o ponto de máximo crescimento corresponde aos 26 dias que as mudas permaneceram in vitro $(\mathrm{y}=-47,005+15,249 \mathrm{x}-$ $\left.0,2883 \mathrm{x}^{2}\right)$.

Os valores obtidos para massa seca de raízes apresentaram comportamento quadrático $(\mathrm{y}=-1,400+1,028 \mathrm{x}-$ $0,0151 \mathrm{x}^{2}$ ) ao longo dos dias de aclimatização, até a data estimada de 33 dias (ponto de máximo da equação). Por outro lado, a taxa de crescimento mostra que o maior acúmulo de massa seca nas raízes é observado nas mudas cujas plantas permaneceram entre 15 e 20 dias no enraizamento in vitro, incrementando um valor equivalente a $0,8 \mathrm{mg}$ em cinco dias.

Esses resultados mostram a dependência da fase de enraizamento in vitro durante a formação das mudas de Gypsophila paniculata na técnica de micropropagação. Também Ault (1994), pesquisando Eriostemon myoporoides, uma outra flor de corte, concluiu que, para obter resultados superiores na aclimatização, a microestaca necessita do período de enraizamento in vitro. Entretanto, esses resultados são contrários aos encontrados por Carvalho et al. (1999), os quais, ao pesquisarem aclimatização de plantas de cafeeiro, concluíram que esta espécie pode ser aclimatizada sem passar pela fase do enraizamento in vitro. Segundo Grattapaglia \& Machado (1998), muitas vezes o enraizamento in vitro pode ser eliminado sem causar danos à plan- 
ta. Entretanto, em muitos casos, o custo extra com o enraizamento in vitro pode ser justificado se este resultar em mudas de melhor qualidade, ou se perdas durante a aclimatização puderem ser reduzidas (George, 1996).

Observou-se, que não houve influência das doses do regulador de crescimento para nenhuma das variáveis estudadas. Provavelmente, esta espécie apresenta níveis endógenos de auxina suficientes para induzir o enraizamento, não necessitando, portanto, de aplicação exógena deste regulador (George,1996).

Kusey et al. (1980), trabalhando com microestacas de Gypsophila paniculata não enraizadas, sem tratamento adicional de auxinas, em casa de vegetação, constataram que, após três semanas de aclimatização, $60 \%$ das microestacas estavam enraizadas e apresentaram alta taxa de sobreviência quando transferidas para o solo. Resultados semelhantes foram encontrados por Seganfredo et al. (1995), com estacas de ameixeira; Pivetta et al. (1999), com estacas de rosa; Akoumianaki-Ioannidou et al. (2000), com estacas de Polygala myrtifolia. Para Carvalho et al. (1999), o uso de AIB em microestacas de Coffea arabica L. prejudica o desenvolvimento das mudas durante a aclimatização.

Desta forma, para produzir mudas de Gypsophila paniculata cultivar Bristol Fairy pela técnica da micropropagação, é necessário realizar o enraizamento in vitro, não sendo possível eliminar essa fase. Entretanto, para as mudas permanecerem no enraizamento in vitro, recomenda-se um período máximo de 25 30 dias e, para melhorar a produção de massa fresca e seca, volume e sobrevi- vência das plantas durante o período de aclimatização, não é necessário utilizar o regulador de crescimento AIB.

\section{AGRADECIMENTOS}

$\mathrm{O}$ primeiro autor agradece à CAPES pela concessão de bolsa de mestrado.

\section{LITERATURA CITADA}

AKOUMIANAKI-IOANNIDOU, A.; KRAVARI, E.; CHRONOPOULOS, J. Propagation of Polygala myrtifolia by cuttings. Acta Horticulturae, v. 541, p. 265-268, 2000.

ASSIS, T.F.; TEIXEIRA, S.L. Enraizamento de plantas lenhosas. In: TORRES, A.C.; CALDAS, L.S.; BUSO, J.A (eds). Cultura de tecidos e transformação genética de plantas. Brasília: EmbrapaSPI/Embrapa-CNPH, 1998. p. 261-296.

AULT, J.R.; In vitro propagation of Eriostemon myoporoides and Eriostemon 'Stardust'. HortScience, v. 29, n. 6. p. 686-688. 1994.

BASSO, S.M.S. Caracterização morfológica e fixação biológica de nitrogênio de espécies de Adesmia DC. e Lótus L. Porto Alegre: UFRGS, 1999. 268 p. (Tese doutorado)

BENINCASA, M.M.P. Análise de crescimento de plantas - noções básicas. Jaboticabal: FUNEP, 1988. $42 \mathrm{p}$.

CALDAS, L.S.; HARIDASAN, P.; FERREIRA, M.E. Meios nutritivos. In: TORRES, A.C.; CALDAS, L.S.; BUSO, J.A.(eds.) Cultura de tecidos e transformação genética de plantas. Brasília: Embrapa-SPI/Embrapa-CNPH, 1998. p. 87-132. CAPELLADES-QUERALT, M.; BERUTO, A.M.; VANDERSCHAEGHE, A.; DEBERGH, P.C. Ornamentals. In: DEBERGH, P.C.; ZIMMERMAN, R.H. (Ed.). Micropropagation, technology and application. London: Kluwer Academic, 1993. p. 215-229.

CARVALHO, G.R., PASQUAL, M.; RESENDE, E.; SCARANTE, M.J.; CARVALHO, G.R. Aclimatização de plântulas de cafeeiro (Coffea arabica L.) propagadas in vitro. Ciência e agrotecnologia, Lavras, v. 23, n. 3, p. 483-490, 1999. DEBERGH, P.C. Aclimatization techniques of plants from in vitro. Acta Horticulturae, v. 289, p. 291-300. 1991.
DEBERGH, P.C.; MAENE, L.J. A scheme for the comercial propagation of ornamental plants by tissue culture. Scientia Horticulturae, v. 14, p. 335345, 1981.

GEORGE, E.F. Plant propagation by tissue culture; Part 2 in pratice. 2.ed. Edington: Exegetics, 1996. $1361 \mathrm{p}$.

GRATTAPAGLIA, D.; MACHADO, M.A. Micropropagação. In: TORRES, A.C.; CALDAS, L.S.; BUSO, J.A. (eds.) Cultura de tecidos e transformação genética de plantas. Brasília: EmbrapaSPI/Embrapa-CNPH, 1998. p.183-260.

HARTMANN, H.T.; KESTER, D.E. Propagación de plantas - principios y practicas. México: Continental, $1990.760 \mathrm{p}$.

KUSEY, W.E.; HAMMER, P.A.; WEILER, T.C. In vitro propagation of Gypsophila paniculata $\mathrm{L}$. "Bristol fairy". HortScience, v. 15, n. 5, p. 600$601,1980$.

MOREIRA, M.F.; APPEZZATO-DA-GLÓRIA, B.; ZAIDAN, L.B.P. Anatomical aspects of AIBtreated microcuttings of Gomphrena macrocephala St.-Hil. Brasilian Archives of Biology and Tecnology, v. 43, n. 2, p. 221-227, 2000.

MURASHIGE, T.; SKOOG, F.A. Revised medium for rapid growth and bio assays with tobacco tissue cultures. Physiologia Plantarum, v. 25, p. 473-497, 1962.

PIERIK, R.L.M. Cultivo in vitro de las plantas superiores. Madrid: Mundi - Prensa, 1990. 326 p.

PIVETTA, K.F.L.; PEREIRA, F.M.; BANZATTO, D.A.; GRAZIANO, T.T. Effect of type of cuttings and indolbutyric acid on the rooting of rose (Rosa sp. 'Red success') leafy cuttings during two seasons. Acta Horticulturae, v. 482, p. 333-338, 1999.

ROGERS, R.B.; SMITH, M.A.L. Consequences of in vitro and ex vitro root iniciation for miniature rose production. Journal of Horticultural Science, v. 67, n. 4, p. 535-540, 1992.

SEGANFREDO, R.; NACHTIGAL, J.C.; KERSTEN, E. Influência do ácido indolbutírico e épocas de coleta de estacas no enraizamento de cultivares de ameixeira (Prunus salicina Lindl.). Revista Brasileira de Agrociência, Pelotas, v. 1, n. 1, p. 40-42, 1995.

TAGLIACOZZO, G.M.D. Fitormônios e seus efeitos biológicos in vitro e in vivo. In: TOMBOLATO, A.F.C.; COSTA, A.M.M. (eds.) Micropropagação de plantas ornamentais. Campinas: Instituto Agronômico, 1998. 72 p. (Boletim Técnico, 174). 